\title{
Trends in worldwide ICT electricity consumption from 2007 to 2012
}

\author{
Ward Van Heddeghem*, Sofie Lambert, Bart Lannoo, Didier Colle, Mario Pickavet, Piet Demeester \\ Department of Information Technology (INTEC) of Ghent University - iMinds, \\ Gaston Crommenlaan 8, B-9050 Gent, Belgium, tel: +32(0)9 3314 977, fax: +32(0)9 3314899
}

\begin{abstract}
Information and Communication Technology (ICT) devices and services are becoming more and more widespread in all aspects of human life. Following an increased worldwide focus on the environmental impacts of energy consumption in general, there is also a growing attention to the electricity consumption associated with ICT equipment.

In this paper we assess how ICT electricity consumption in the use phase has evolved from 2007 to 2012 based on three main ICT categories: communication networks, personal computers, and data centers. We provide a detailed description of how we calculate the electricity use and evolution in these three categories.

Our estimates show that the yearly growth of all three individual ICT categories $(10 \%, 5 \%$, and $4 \%$ respectively) is higher than the growth of worldwide electricity consumption in the same time frame (3\%). The relative share of this subset of ICT products and services in the total worldwide electricity consumption has increased from about $3.9 \%$ in 2007 to $4.6 \%$ in 2012 . We find that the absolute electricity consumption of each of the three categories is still roughly equal. This highlights the need for energy-efficiency research across all these domains, rather than focusing on a single one.
\end{abstract}

Keywords:

Green ICT, energy-efficiency, power consumption, electricity consumption, footprint

\section{Introduction}

ICT is everywhere - Information and Communication Technology (ICT) devices and services have profoundly changed the way in which humans work, travel, play and interact in the last decades. An increasing number of people earn their living working in front of a computer, and many industrial and agricultural processes have in some way become controlled or monitored by intelligent electronic devices. Many cars are now equipped with a Global Positioning System (GPS) device for easier navigation on unfamiliar roads and time-of-arrival estimation, even taking into account traffic jams and road works. Entertainment has a rising digital footprint in the form of video games, online games, and in-house intelligent workout devices. The steep rise of online social services such as Facebook (over one billion users near the end of 2012 [1]) and the continued proliferation of mobile phones show that inter-human communication and interaction are increasingly taking place via digital platforms.

There is no single metric for the ICT footprint - The increase of ICT equipment has an associated growing impact on our environment. This impact comes in many forms, and is often expressed as a 'footprint'. For example, the manufacturing and usage of ICT equipment have an associated energy footprint and $\mathrm{CO}_{2}$ emission footprint. Pollution associated with mining for rare earth metals, and waste through improper disposal of

\footnotetext{
${ }^{*}$ Corresponding author

Email address: ward. vanheddeghem@intec. ugent. be (Ward Van Heddeghem)
}

broken or end-of-life equipment can also be considered as part of the environmental footprint. As such, depending on which aspects are taken into account, there are several methodologies to measure and determine the footprint of organizations, services and goods with respect to ICT. The ICT-footprint initiative [http://www.ict-footprint.com], which was initiated by the European Commission, aims to find a global consensus in the ICT industry for a common definition and measurement framework within this respect. Several existing methodologies are listed on the website of the ICT footprint initiative.

Footprint scope of this work - In this work we only consider the use phase electricity consumption of a number of important ICT equipment categories. For ICT equipment, the use phase has been shown to make up a large fraction of total carbon emitted during manufacturing, usage and end-of-life activities (see e.g., in [2] and [3]), and for personal computers the survey in [4] concludes that the use phase is the dominant life cycle phase for primary energy demand. We only focus on the electricity consumption, as the use phase carbon emissions can be directly calculated from the emission intensity of the electricity (i.e., the amount of $\mathrm{CO}_{2}$ emitted per produced $\mathrm{kWh}$ ). We do not distinguish between the electricity source being either on-grid (i.e., from a utility provider) or off-grid (such as a remote mobile base station powered by a diesel generator or solar panels). Where applicable, we do include the electricity consumption associated with cooling and power provisioning of ICT equipment in operation. While it could be argued that this broadens the scope somewhat beyond ICT equipment, we feel this is appropriate as this overhead electricity use is directly and strongly tied to 
that of the ICT equipment itself. To conclude, the use phase electricity consumption is a relevant factor in the overall ICT footprint, and therefore merits a dedicated, detailed study.

The purpose of estimating ICT electricity use - The relevance of estimating the worldwide ICT electricity use is twofold. A first purpose is to assess whether ICT is a significant contributor to the worldwide electricity consumption, or by extension, to the worldwide carbon emissions. Such an assessment is not limited to the current situation, but given projected growth trends, also provides insight in the evolution of the ICT electricity share in the near future. A second purpose is to assess where efforts should be concentrated in order to reduce the worldwide ICT electricity consumption. Energy-efficiency efforts can only have a meaningful impact if they are focused on those areas or categories that contribute most-or are expected to do so in the near future - to the total ICT electricity consumption.

Earlier work on worldwide ICT footprint estimation - There have been a number of earlier studies that estimate the worldwide ICT electricity use. In 2008, the SMART2020 report [3] explored the potential of ICT to reduce global carbon emissions, and while doing so provided an estimation and projection of the ICT footprint itself. In the same year, some of the co-authors of this current paper also published a study [5] to estimate the worldwide electricity use and embodied energy associated with ICT equipment and services. Finally, a study by Malmodin et al. [2] that appeared in 2010, provided an estimate of the 2007 worldwide greenhouse gas emissions and operational electricity use in ICT. Incidentally, while we were finalizing our current study, the SMARTer2020 report [6] appeared at the end of the year 2012. It provides an updated version of the earlier report based on more recent data and findings. We have intentionally refrained from using data provided in [6] for our current work, in order to have an independent assessment.

Goal and contributions of this paper - The main goal of our current work is to provide an update of our earlier estimates published in 2008. Even more importantly, we want to explore the trends over the last five years, i.e. from 2007 to 2012, and see if there are significant differences in growth rates compared to earlier years. We estimate the worldwide electricity consumption of communication networks (Section 2), personal computers (Section 3) and data centers (Section 4). An overview is given in Fig. 1. We consider the use phase only; the electricity used to manufacture and dispose of equipment is not included. While our initial objective was to cover again the same five categories as we did in our previous work, we do not provide a detailed estimation of the electricity consumption of the TVs category and Others category, as we did not have sufficiently reliable data available for doing so. This is in itself not a major issue, as we can assess general trends for the available three categories, as described in Section 5. Finally, to assess the validity of our results, we perform an extensive comparison of our findings with the aforementioned earlier works (Section 6).

\section{Communication networks}

In preparation of this paper, we first performed a detailed estimation of worldwide electricity use of communication networks

\section{SCOPE OF THIS STUDY}

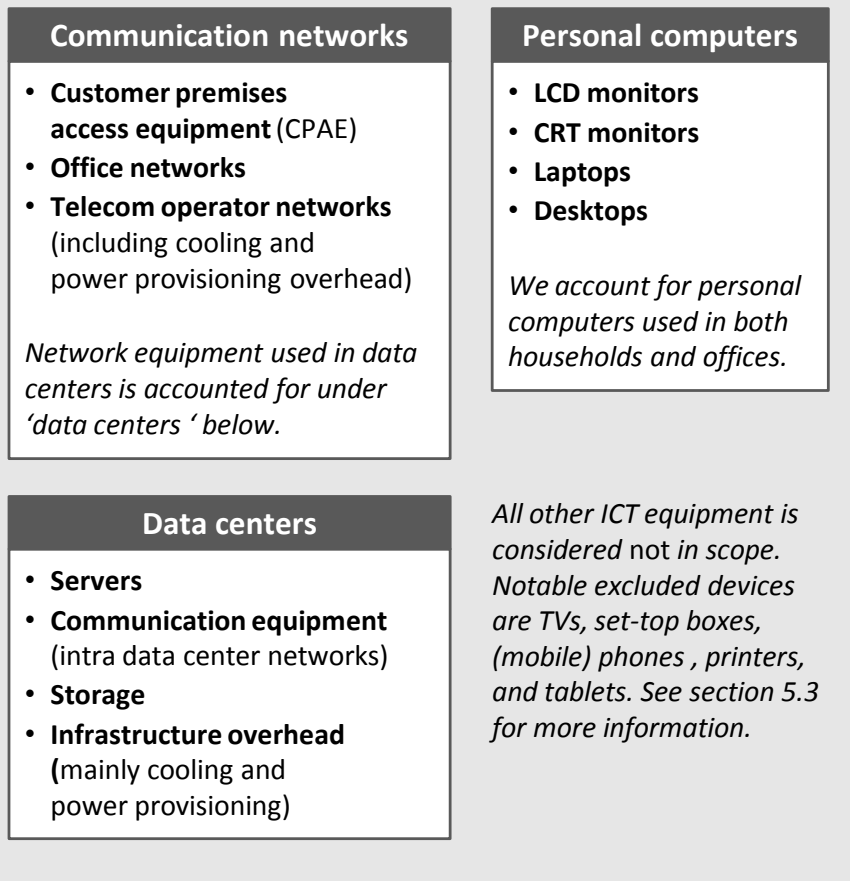

Figure 1: The scope of ICT equipment that we consider in this study.

in the time frame 2007 to 2012, which was published in [7]. In this section we only provide a summary of these results; more detailed numbers and an in-depth explanation on the methodology can be found in the cited work. An important revision is the updated office networks estimation as we discovered that the potential double accounting for data center network equipment was larger than assumed in [7]. As a result the office network electricity use is now down to about half of our earlier estimate. We also renamed customer premises equipment to customer premises access equipment to make the scope less ambiguous.

We consider three components of communication networks: (a) telecom operator networks, (b) office networks and (c) customer premises access equipment. The electricity use of telecom operator networks excludes the electricity consumption in their offices and their data centers, as these are dealt with separately in Section 2.2 and Section 4; the electricity consumption of retail associated with telecom operators is considered out of scope. Electricity use in office networks includes routing, switching, WLAN, and network security equipment in offices. Finally, customer premises access equipment covers residential access equipment, which consists mainly of modems and routing equipment with or without Wi-Fi functionalities.

In the text below, we first describe the methodology used to assess the electricity consumption of the three subcategories, before presenting the results and a discussion on the reliability of our estimates.

\subsection{Telecom operator networks}

We estimate the worldwide electricity use for operator networks based on the electricity consumption of a selection of 
telecom providers. We extrapolate these operator specific values using worldwide numbers of mobile, fixed broadband and fixed telephone subscriptions.

Our approach differs from earlier approaches to estimate the worldwide electricity consumption, which are typically based on first determining the average electricity consumption per service per subscriber, through one of the following two general techniques. On the one hand, a bottom-up approach can be used, as was done by the authors in [8,9]. They summed the power consumption of individual network components (such as routers, optical amplification systems and mobile base stations) to estimate the electricity consumption, per user or per unit of traffic, for a given service. These per-service consumption values were then multiplied with worldwide total traffic per service to get the total worldwide electricity consumption per service. On the other hand, in [2] a top-down approach was used: based on the aggregated power consumption data from a number of telecom operators, the authors determined the average electricity consumption per mobile subscriber and fixed subscriber. Multiplying these values with worldwide subscription numbers and summing the results provided them with an estimate for the worldwide electricity consumption in telecom operator networks. However, accurately determining a worldwide average electricity consumption per service per subscriber is not easy, because equipment is often shared across different services. For example, fixed and mobile services can use a single backbone network.

In order to circumvent the issue of assigning the power consumption of an operator to specific services, we use a subscription-based representative sample of operators. In our representative sample, the number of mobile, fixed broadband and fixed telephone subscriptions have the same relative ratios as the worldwide subscription numbers. The power consumption for this sample is then scaled up to a worldwide value by multiplying with a single scaling factor. This scaling factor is the ratio of worldwide subscriptions over the subscriptions covered in the sample, which, following the definition of the representative sample, is the same for mobile, fixed broadband and fixed telephone services. Using this approach, we don't have to determine the average power per user.

The use of a representative sample (as opposed to just taking a random combination of telecom operators) is required because we believe the power consumption per user for each of these services can differ significantly, and operators might have an unbalanced number of subscriptions for a particular service. For example, while China Mobile is by far the largest operator in our sample (in number of subscriptions), its focus is almost exclusively on mobile subscriptions. Not taking this unbalance into account would lead to worldwide electricity consumption values which are skewed by the power consumption per mobile subscriber, which can be very different from the (also unknown) power per fixed broadband or fixed telephony subscriber. Furthermore, incumbent operators often lease parts of their networks to other operators. This means that the number of customers connected to a network is not necessarily the same as the number of subscribers reported by the operator, making it difficult to determine the average electricity consumption per connected user. To cancel out the effect of leased lines as much as possible, we aggregate the subscriptions and electricity consumption of different operators.

One drawback inherent to our approach is that we cannot determine the relative contributions of different services (mobile, fixed broadband, and fixed telephone) or network sections (such as access, metro and core) to the total network electricity consumption, since we aggregate the electricity consumption for all services from the sample.

\subsection{Office networks}

The scope of this section is the electricity used by network equipment in offices, excluding network equipment in data centers. This includes network equipment in network operator offices but excludes equipment in the telecom network they operate (this was already accounted for in section 2.1). We do not consider custom enterprise transport networks, such as those between Google or Amazon data centers; their power consumption will very likely be negligible as optical transport networks consume very little compared to other network equipment such as modems, IP routers or base stations.

We base our estimate on a study by Lanzisera et al. [10], which estimates the USA and worldwide electricity consumption of data network equipment in both residential buildings and offices. Their study focuses on IP-based network equipment only, and does not include the electricity used by power or cooling infrastructure. Their annual electricity consumption estimate is based on an average power consumption per device, and uses values for 2007 and 2008 with forecasts from 2009 through 2012, which we have adopted. We consider only the equipment relevant in office use, and we add an estimated overhead for cooling for each of the equipment categories, i.e. switches, routers, WLAN equipment and security equipment.

We discovered that in the earlier results published in [7], we underestimated the potential double accounting for data center network equipment ${ }^{1}$. Therefore, we re-evaluated our estimate. In [7] we only considered the following five categories from the study by Lanzisera: 10/100 Mb/s switches, 10/100/1000 Mb/s switches, small \& medium routers, enterprise WLAN devices, and small \& medium security appliances. In this study we include three extra equipment categories in our calculation: modular \& 10G switches, large routers, and large security appliances. These three categories broaden the scope to completely cover all data center network equipment as well. To exclude telecom operator network equipment (which was already covered in Section 2.1), we consider only half of the electricity use reported in [10] for the modular \& $10 \mathrm{G}$ switches and large routers. We do not have data to more accurately assess the share of operator network consumption in both categories; assuming the share to be half minimizes the potential deviation. As the sum of both categories contributes less than $10 \%$ of the total electricity use,

\footnotetext{
${ }^{1}$ In [7] we incorrectly reported the network equipment for data center volume servers to potentially account for $1.48 \mathrm{TWh}$ (or only $5 \%$ of the total uncooled office network electricity consumption). However, the value given was in GW, which corresponds to almost $13 \mathrm{TWh}$ instead of $1.48 \mathrm{TWh}$.
} 
Table 1: Office networks: cooling overhead factors and worldwide electricity use per type of equipment (electricity use estimates are adaptations of the values in [10]). The share of communication networks in data centers (determined in Section 4) is subtracted to avoid double accounting.

\begin{tabular}{lcrrr}
\hline & $\begin{array}{c}\text { Cooling } \\
\text { overhead } \\
2007 / 2012\end{array}$ & $\begin{array}{r}\text { Electricity } \\
\text { use, 2007 } \\
\text { (TWh) }\end{array}$ & $\begin{array}{r}\text { Electricity } \\
\text { use, 2012 } \\
\text { (TWh) }\end{array}$ & Note \\
\hline switching - 10/100 & 1.38 & 12.7 & 10.7 & \\
switching - 10/100/1000 & 1.38 & 5.4 & 17.5 & \\
switching - mod./10G & $1.95 / 1.83$ & 3.9 & 4.3 & a, b, c \\
routers - small \& med. & 1.75 & 3.5 & 4.2 & \\
routers - large & $1.95 / 1.83$ & 1.0 & 0.4 & a, b, c \\
enterprise WLAN & 1.00 & 1.0 & 2.3 & \\
security - small \& med. & 1.75 & 5.3 & 7.7 & \\
security - large & $1.95 / 1.83$ & 2.9 & 4.0 & a, b \\
\hline Data center networks & $1.95 / 1.83$ & -23.4 & -28.9 & b \\
\hline Total & & 12.2 & 22.2 & \\
\hline
\end{tabular}

${ }^{a}$ Equipment type not accounted for in [7]

b Power Usage Effectiveness (PUE) value for 2007 / 2012, from Table 3

${ }^{\mathrm{c}}$ Half of the value specified in [10], to avoid counting the telecom operator share

the potential error will be small. We also subtract the data center network equipment electricity consumption (which can be derived from Table 3 in Section 4) to avoid overlap between the categories.

The details and results are given in Table 1. The worldwide office network equipment is estimated to consume $22 \mathrm{TWh}$ in 2012 (instead of 42 TWh as reported earlier in [7]).

\subsection{Customer Premises Access Equipment (CPAE)}

In this section, we consider the electricity consumption of residential network access equipment. In order to access the network, every Internet subscriber requires a modem. Most users also have a $\mathrm{Wi}-\mathrm{Fi}$ router installed, often with integrated wired switching and routing capabilities. The modem and Wi-Fi router may also come in a single box. We estimate the worldwide power consumption by multiplying average power consumption values of these residential devices per access technology category with the number of subscriptions per category. We consider the following access technologies: cable, Digital Subscriber Line (DSL), Fiber To The Home (FTTH), narrowband, and other broadband (such as satellite). Our scope does not include residential stand-alone wired switches, but they have been estimated in [10] to be only a small contributor. Similarly, we do not include power line communication devices; we estimate ${ }^{2}$ that their consumption is around $2 \mathrm{TWh} / \mathrm{y}$, but an in-depth study would be needed for a more accurate evaluation.

The number of worldwide users for each category is based on various sources: the worldwide average number of broadband subscriptions per 100 inhabitants [14], worldwide population data [15] and access technology distribution [16, 17, 18].

\footnotetext{
${ }^{2}$ HomePlug is the dominant standard for power line communication devices. The HomePlug Powerline Alliance reported over 60 million installed devices in 2010 [11]. With an estimated electricity consumption of $4 \mathrm{~W}$ per device (based on a number of data sheets, e.g. $[12,13])$ ), this results in $2.1 \mathrm{TWh} / \mathrm{y}$.
}

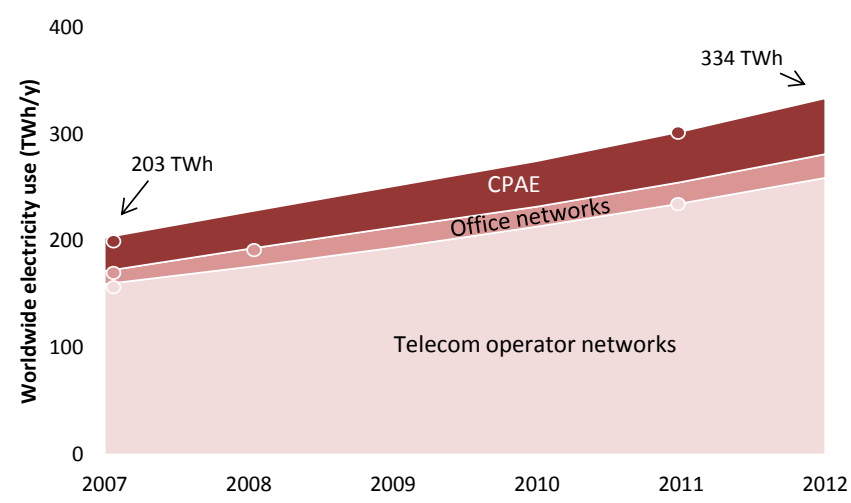

Figure 2: Worldwide use phase electricity consumption of communication networks. The annual growth is $10.4 \%$ in the 2007 to 2012 time frame. Telecom operator networks dominate the result. The circular markers $\circ$ indicate years for which the subcategory results are (mainly) based on data for that specific year; non-marked data points are (mainly) interpolations or extrapolations.

Values for 2012 are extrapolations based on data from previous years. The power consumption per user values for cable, DSL and FTTH are based on [10, 19]. For the relatively small number of users accessing the Internet through other broadband technologies we assumed a power consumption comparable to that of the more common broadband technologies. The per user power consumption for narrowband users is based on the power consumption of a dial-up modem [20].

\subsection{Results}

The total worldwide electricity consumption in communication networks grew from $200 \mathrm{TWh}$ per year in 2007 to $330 \mathrm{TWh}$ per year in 2012 , corresponding to an annual growth rate of $10.4 \%$ (see Fig. 2).

Telecom operator networks power consumption makes up $77 \%$ of this value, customer premises access equipment about $15 \%$ and office networks only around $7 \%$. The annual growth rate of office networks is highest with $12.8 \%$, whereas the other two categories grow at a slightly lower rate of $10.2 \%$ (telecom operator networks) and $10.8 \%$ (customer premises access equipment).

It is interesting to note that a number of studies that use a bottom-up approach to estimate the communication networks electricity use, attribute a much larger relative share to customer premises access equipment than we do, e.g., [9, 21, 22]. For $[9,21]$, we believe this to be because of the constraints inherent to a bottom-up approach, which might not easily account for such things as legacy equipment, underutilized equipment, or unknown overhead in general. Furthermore, it is important to be aware of the considered scope of customer premises access equipment when comparing results; e.g., the 'home networks' category in [22] includes not only access equipment but also DECT telephones, set-top boxes and laptops and computers.

\subsection{Reliability}

For the telecom operator networks calculations, we based ourselves on aggregated operator power consumption values 
(rather than averaging and upscaling power per subscriber values) to minimize the effect of leased and rented lines. This effect may have an influence nonetheless. Secondly, our results are-for the most part—based on publicly available electricity consumption values. As companies that publish these values are typically those that have already made efforts to improve their energy-efficiency, this may lead to overly optimistic results.

For our office networks estimations, there is some uncertainty in (a) the cooling overhead factors, as they are based on limited discussions with industrial experts, and (b) whether we accounted sufficiently for the overlap in scope with telecom operator networks. Smaller switching equipment (i.e., 10/100 and 10/100/1000 switches) will also be present in telecom operator networks, but it is unclear which fraction it represents in both switching categories in Table 1, and we did not account for it. This makes our estimation for office networks electricity consumption an overestimation. In any case, as office networks contribute less than $7 \%$ to the overall communication networks result, the influence of potential scope overlap on the overall result will be very small. To get an indication of the reliability of our result, it is instructive to estimate the electricity use of office network equipment per office computer, similar to what was done by Kawamoto et. al. [23]. With 548 million office computers in 2012, we get $4.6 \mathrm{~W} /$ unit. While this seems to be in line with the $3.8 \mathrm{~W} /$ unit reported by Kawamoto (in 2002), he does not account for cooling and does not include WLAN and security equipment in his calculation (which would result in a higher value). Malmodin et al. [2] report a value of $8 \mathrm{~W} / \mathrm{unit}$. But, as detailed in Appendix S8 of the supporting information for [2] this value includes 'faxes and other business systems' which accounts for over half of the total office network equipment consumption (or about $4 \mathrm{~W} / \mathrm{unit}$ ). As office end-user equipment is not in our scope, this would explain our lower overhead per office personal computer. So part of the large variation in watts per office personal computer seems to be explained by a different scope of office network equipment.

The reliability of our customer premises access equipment results depends strongly on the accuracy of our power per user estimates, which are based on averages for the USA. We were unable to the determine the evolution of average power consumption per device from 2007 to 2012 . However, we do take into account shifts between different technology categoriesthe decrease in narrowband and increase in FTTH being the most notable-which leads us to believe the general trend in our results provides a good estimate of the evolution in power consumption of customer premises access equipment. Finally, it might be interesting to note that Lanzisera's [10] CPAE estimate is based on OECD countries (which currently do not include emerging economies such as Brazil, Russia, India, and China). As a result, our customer premises access equipment estimates (which do include all countries) are substantially higher.

\section{Personal computers}

The Personal Computers (PCs) category covers the electricity consumption of desktops, laptops and (external) monitors connected to computers. We exclude terminals connected to the
Table 2: Personal computers and computer monitors: average energy consumption per device (taking into account active and inactive times) and worldwide electricity use per type of equipment.

\begin{tabular}{lrrrr} 
& \multicolumn{2}{c}{$\begin{array}{c}\text { Energy/device } \\
(\mathrm{kWh} / \mathrm{y})\end{array}$} & \multicolumn{2}{c}{ Worldwide energy } \\
& 2007 & 2012 & 2007 & 2012 \\
\hline Office desktops & 149 & 137 & 51.4 & 46.2 \\
Household deskt. & 231 & 213 & 91.2 & 105.9 \\
Office laptops & 46 & 39 & 4.1 & 8.3 \\
Household lapt. & 70 & 59 & 17.7 & 45.2 \\
Total computers & & & 164.4 & 205.6 \\
\hline CRT monitors & 175 & 175 & 46.6 & 31.9 \\
LCD monitors & 70 & 70 & 27.9 & 69.6 \\
Total monitors & & & 74.5 & 101.5 \\
\hline Total & & & 238.9 & 307.1 \\
\hline
\end{tabular}

mainframe and devices such as smart-phones or tablets that have only some, but not all, of the functions of a PC (e.g. they may lack a full-sized keyboard, a large screen, ...) [24].

We calculate the worldwide energy consumption by multiplying average energy consumption values per device by numbers of devices. We distinguish between household and office desktops and laptops, and Cathode Ray Tube (CRT) and Liquid Crystal Display (LCD) monitors, as listed in Table 2.

\subsection{Number of personal computers}

We estimate the worldwide number of PCs based on the average number of PCs per 100 inhabitants for each country [25] and population data for these countries [15] (we used the medium variant for population prospects). There are some gaps in the United Nations (UN) data for the number of PCs per 100 inhabitants. For some countries the data is missing for one or two years. We fill in these blanks by making a linear interpolation of the previous and the next year for which data is available. For other countries there is little or no data available, so we can't interpolate data from other years. We assume the number of PCs per 100 inhabitants in these countries equals the average value for the region they belong to. Based on these assumptions, we estimate the total number of PCs per region and worldwide for 2000-2006. From 2007 onwards, there is not enough data available in the UN database to make a reliable estimate.

However, annual PC sales numbers are available for 19912010 [26]. If we know the lifetime distribution of PCs, we can use these sales data to determine the number of PCs in use in 2007-2010. We model the lifetime distribution of personal computers as a curve that is initially flat, followed by an exponential decay. This curve is characterized by two parameters: the threshold and the decay constant. Based on the number of personal computers in use in 2000-2006 and the sales data for 1991-2006, we estimate the threshold of the lifetime curve is at 2.5 years, after which $26 \%$ of the PCs still in use are discarded each year. This corresponds to an average lifetime of 5.9 years. Combining this lifetime model with historical sales data (and an exponential extrapolation of this sales data to predict sales in 2011-2012) provides us with an estimate for the number of PCs in use in 2007-2012. 
Based on these calculations we estimate over 1 billion personal computers were in use in 2007 . We estimate this number has increased to just over 1.8 billion by the end of 2012 .

\subsection{Number of laptops and desktops, and household and office computers}

Laptops typically consume much less energy than desktops. We therefore need an estimate of the number of laptops and desktops that are in use. This can be derived indirectly from the annual sales data for laptops and desktops [26, 27] and the lifetime model of personal computers we determined in the previous section. The share of laptops has known a strong increase in the past five years, from about $32 \%$ of the installed base of personal computers in 2007 to $54 \%$ in 2012.

A distinction is made between computers that are used in an office environment and computers that are used in households, since the usage patterns in these environments differ. In [19]-a study on the electricity consumption of consumer electronics in households - the number of desktops and laptops in USA households are given. Combining these numbers with the total installed base of laptops and desktops in the USA (obtained in the calculations in the previous paragraph) allows us to estimate the distribution of computers per type (laptop/desktop) and environment (household/office). We assume the worldwide distribution is similar to that in the USA.

\subsection{External monitors}

The screens integrated in laptops were already taken into account in the previous section, but we still need to consider external displays attached to most desktops and some laptops. Unfortunately we could not find any worldwide estimates for the number of computer monitors that are currently in use. In [19], survey results for the year 2010 indicate that in USA households there are on average 0.96 external displays connected to a desktop $^{3}$, and there are on average 0.26 external displays connected per laptop. We assume these fractions apply to all laptops and desktops worldwide to obtain the worldwide number of external computer monitors in use in 2010 . We can't simply apply these fractions for other years as well, since the number of computer monitors per device has increased over the years. To estimate the growth rate for the number of monitors, we also use data from the USA study, where the number of computer monitors in households in 2005, 2006 and 2010 are given. Based on these numbers we expect the number of monitors to increase by $12.06 \%$ annually. We apply this growth rate to the 2010 value we obtained above to estimate the worldwide number of monitors for 2006-2012.

We make a distinction between CRT and LCD monitors, since the latter are more energy efficient. We did not find historic trends for the percentage of CRT displays in use in all regions, but we are able to derive the penetration curve of CRTs in the USA installed base from values for 2006-2010 in [19] and the

\footnotetext{
${ }^{3}$ It might be surprising that there is on average slightly less than one monitor per desktop computer. As the study notes: 'this is partly due to the prevalence of all-in-one PCs, i.e. those with integrated displays'.
}

fact that the first LCD monitors were commercially available around 1999 [28]. We then use the difference in transition time from CRT to LCD TVs (in sales data) as an indication for how many years we should offset the USA curve in time for other regions. For example, Indian LCD TV shipments surpassed those of CRT TVs in 2012, while the USA and Europe saw their LCD TV shipments exceed those of CRTs in 2007. This means that we shifted the curve for the percentage of CRT monitors in India 5 years into the future. Combining these curves with the installed base of computers per region provides us with a weighted average for the percentage of CRT and LCD monitors in use worldwide.

\subsection{Power consumption per device}

To the best of our knowledge, there are no worldwide values available for the average power consumption of desktops and laptops. One of the main challenges when determining the average power consumption of these devices is that even though the numbers for power consumption in active, sleep and off mode are known, we have no recent information on how many hours computers are left on and in sleep mode during the day. Although there are no worldwide averages available, we did find average values for the USA [19], so we derived our estimates from these numbers as follows. The work in [19] provides average per-device power consumption values for desktops and laptops in USA households for 2010, as well as a comparison to values for 2006 from a previous study. Based on these numbers we estimate the evolution in power consumption per household desktop and laptop for 2007-2012. Additionally, [19] references studies on the power consumption of office desktops and laptops, giving a value for 2005 and 2009 respectively. We assume the ratio of office to household power consumption remains constant to obtain the per-device power consumption values for office desktops and laptops.

Based on a study on the carbon emissions associated with ICT in Australia [29] and the previously mentioned study on the energy consumption of consumer electronics in USA homes [19] we obtained an average annual energy consumption value for CRTs and LCDs.

\subsection{Result}

The final results of our calculations are given in Table 2 and shown in Fig. 3. The total energy consumption by personal computers and their displays is currently around 300 TWh per year. The annual growth rate of this total electricity consumption over the time frame 2006 to 2012 is $5.3 \%$. This growth rate is significantly lower than for device numbers (which is around 11-12\% for computers and monitors), mainly due to the growing popularity of laptops and LCD monitors, which are more energy efficient than desktops and CRT monitors.

\subsection{Reliability}

In our calculations we had to make some assumptions where we could not find the required data. To the best of our knowledge, there are no recent statistics available for the time an average computer spends in active, sleep and off mode. These 


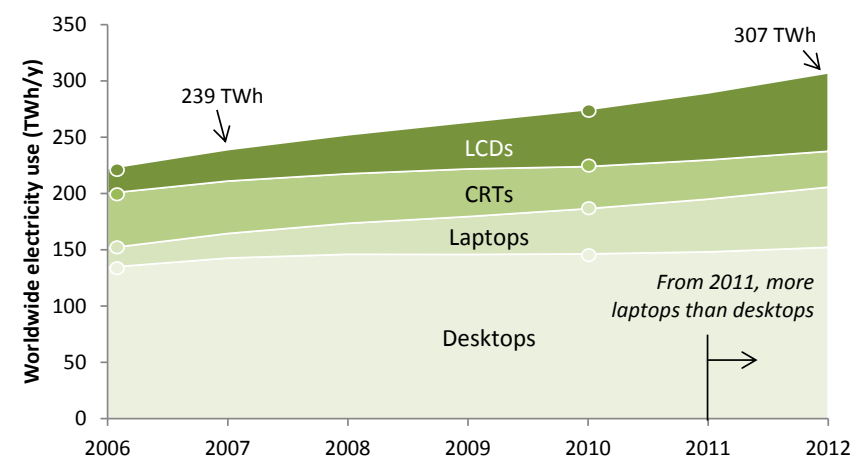

Figure 3: Worldwide use phase electricity consumption of personal computers. Desktops still dominate the result. The shift to more energy-efficient technologies has tempered overall electricity use: while the number of desktops+laptops has grown at $10.9 \%$ per year from 2007 to 2012 , the electricity consumption has only grown at $5.1 \%$ per year. The circular markers $\circ$ indicate years for which the subcategory results are (mainly) based on data for that specific year; non-marked data points are (mainly) interpolations or extrapolations.

parameters have a considerable influence on the average power consumption of $\mathrm{PCs}^{4}$, so it would be interesting to have more (worldwide) data available on this topic. Comparing the active, sleep and off times to the time PCs are actually used would also enable an estimation of the power savings that can still be achieved through the introduction of more intelligent power management. There are some estimates of the average energy consumption by PCs available in literature, but these are often national averages and are only available for more developed economies. This raises questions on the representativity of these values when we estimate the worldwide energy consumption. Furthermore, the values we did find in literature sometimes show a large spread. For example, according to [30], an average laptop in Europe consumed $116 \mathrm{kWh} / \mathrm{y}$ in 2007 and an average laptop in Switzerland consumed $47.5 \mathrm{kWh} / \mathrm{y}$ in 2008 , while in [19] the average energy consumption of a laptop in the USA is estimated at $72 \mathrm{kWh} / \mathrm{y}$. It is clear that further research in this area could greatly increase the reliability of our estimates.

While we have a reliable estimate for the number of personal computers in use based on UN statistics, the number of (external) computer monitors was harder to assess. Our calculations were complicated by the fact that shipping data for computer monitors is not publicly available. Our estimate for the number of devices is based on USA data solely, and would be more reliable if averages for different regions could also be found. Moreover, the availability of detailed shipping numbers would allow us to obtain more reliable estimates of the average power consumption of computer screens.

The influence of changes in individual parameters on the combined end result is however limited in most cases, which leads us to believe our results are a good indication of the worldwide annual energy consumption by personal computers and computer monitors.

${ }^{4}$ For example, a PC that is fully on for 8 hours/day and 5 days/week (i.e., a typical work week) and turned off otherwise, consumes only about $25 \%$ of the power consumption of a PC that is on all the time.

\section{Data Centers}

In the data center category we cover the worldwide power consumption associated with computer servers, whether located in large data centers or in smaller spaces such as office server rooms. To estimate the total electricity used by data centers worldwide in the time frame 2007 to 2012, we base ourselves on the latest study by Koomey on this topic [31]. Koomey provides an estimation of data center power consumption for 2005, and a lower and upper bound estimation for 2010. We use newer data to estimate a most likely value instead of an upper and lower bound for 2010, and extend these trends to 2012. A key difference is that we include electricity use attributed to so-called 'orphaned servers', i.e., a typically undocumented number of servers using electricity but no longer delivering services.

The data center power consumption calculation follows the methodology outlined in [31]. To get the worldwide electricity consumption of servers we multiply, for each of three server classes, the average power per server by the number of servers worldwide. We then add the electricity used by storage equipment (tapes and hard disks), communication equipment (such as network switches) and infrastructure equipment (such as cooling and power provisioning losses) by applying three overhead factors. See also Table 3.

We consider Koomey's (i.e., IDC's) three cost-based classes of servers: volume servers $(<\$ 25000$ per unit), mid-range servers (between $\$ 25000$ and $\$ 500000$ per unit) and high-end servers (> \$500 000 per unit). As the server count for these classes is based on commercial estimates, it does not account for custom-made servers from companies like Google or Amazon. Koomey has shown the impact of these servers to be still relatively small [31]. Custom-made servers might become a factor to consider in the future, however.

\subsection{Electricity use per server}

In [31], the 2010 lower bound scenario assumes no growth in power per server since 2005 (to reflect the industry's increased focus on energy-efficiency), whereas the upper bound scenario assumes the power per server trends from 2000 to 2005 extend beyond 2005 .

To get recent data on the electricity use per server we used data available at spec.org, a non-profit corporation that establishes performance and power consumption benchmarks for computers. We analyzed the server power consumption (at $50 \%$ average target load) for all servers up to $1000 \mathrm{~W}$ in the spec.org power database [32] between January 2008 and December 2012 (393 entries). We created a volume and mid-range cluster by separating at $350 \mathrm{~W}$ (based on the power per server in 2005). We assumed $1000 \mathrm{~W}$ as an upper bound for the mid-range servers; few data points higher than this value were available anyway. The volume servers cluster (340 entries) shows a -3\% Compound Annual Growth Rate (CAGR) in power per server in the period 2008-2012, and the mid-range servers cluster (53 entries) shows a $0 \%$ CAGR (i.e., no change) for the same period. The high-end cluster is not captured at all by the sample. A sensitivity analysis of the resulting volume and mid-range CAGR values to the cluster separation value, shows that the volume server CAGR is 
Table 3: Worldwide power consumption of data centers in 2007 and 2012. We adapted data from [31] by including orphaned servers, assuming no growth in the power per device since 2005, and assuming the server installed base grew from 2010-2012 as it did in 2005-2010.

\begin{tabular}{|c|c|c|c|c|c|c|}
\hline Server class & Volume & $\begin{array}{c}2007 \\
\text { Mid-range }\end{array}$ & High-end & Volume & $\begin{array}{c}2012 \\
\text { Mid-range }\end{array}$ & High-end \\
\hline Power per server & $222 \mathrm{~W}$ & $607 \mathrm{~W}$ & $8106 \mathrm{~W}$ & $222 \mathrm{~W}$ & $607 \mathrm{~W}$ & $8106 \mathrm{~W}$ \\
\hline Number of servers (including orphaned servers) & \multicolumn{6}{|c|}{ Installed base $\times 1.25$} \\
\hline Storage power consumption & \multicolumn{6}{|c|}{$24 \%$ of total server power consumption } \\
\hline Communication power consumption & \multicolumn{6}{|c|}{$15 \%$ of total server power consumption } \\
\hline Total power consumption & $176 \mathrm{TWh}$ & $21 \mathrm{TWh}$ & $19 \mathrm{TWh}$ & $219 \mathrm{TWh}$ & $15 \mathrm{TWh}$ & $34 \mathrm{TWh}$ \\
\hline
\end{tabular}

relatively stable at $-3 \%$ (ranging from $-3 \%$ to $-2 \%$ in the cluster separation interval of $225 \mathrm{~W}$ to $475 \mathrm{~W}$ ), whereas for the midrange servers, the CAGR varies from an significant increase in power per server (6\% per year, at $250 \mathrm{~W}$ cluster separation) to a negligible decrease.

We chose not to apply these CAGR values directly in our calculations since the spec.org sample is probably biased towards more energy-efficient servers. However, as volume servers dominate by far the server power consumption, these trends do suggest that the increase in power per server from 2000-2005 reported in [31] has not continued. Therefore we assume for all years in the time frame 2005 to 2012 the same power per server values as reported for the year 2005 in [31]. These values for each of the three server classes are listed in Table 3.

\subsection{Worldwide number of servers}

The worldwide number of servers for 2005 and 2010 is reported in [31]. For the worldwide number of servers in 2011 and 2012, we assume that the 2005 to 2010 server growth trends reported in [31] have continued to 2012. These trends showed a slower growth of volume servers $(5.9 \%$ p.a.), a decrease in midrange servers $(-5.3 \%$ p.a.), and an increased growth of high-end servers (13.1\% p.a.).

We assume continued trends based on the IDC server shipment data reported for 2011 [33] and 2012 [34]. The data we have available from IDC only details the total server shipments (i.e, the sum of all three server classes). However, the strong domination of the volume servers in the total number of shipped servers (for 2010, volume server shipments represented $98 \%$ of the total server shipments [31]) allows us to use the IDC data as indicative for volume server trends. The IDC data suggests a growth in the server installed base from 2010 to 2012 that is only slightly higher than the $5.9 \%$ p.a. rate observed from 2005 to 2010 .

We adjust the number of servers above (i.e., the 'installed base') upwards with a factor 1.25 to account for orphaned servers, i.e., about $20 \%$ of the servers in many data centers are using electricity but no longer delivering computing services. In [31], orphaned servers are estimated to be $10-30 \%$ of the servers based on anecdotal evidence. Assuming an average value of $20 \%$, this results in a factor of $20 / 80=25 \%$ relative to the reported installed base.

Both the server worldwide installed base and the orphaned correction factor are shown in Table 3.

\subsection{Storage, communications and infrastructure overhead}

In line with [31], the storage and communication equipment power consumption is added as a fixed percentage of the server power consumption, i.e. $24 \%$ and $15 \%$ respectively.

The infrastructure equipment comprises cooling, power provisioning and power backup systems. Its power consumption is commonly captured by the Power Usage Effectiveness (PUE), a factor $\geq 1$. For example, a PUE of 2 implies that for each watt of IT electricity use (i.e., by servers, storage and communication equipment), an additional watt is consumed by the infrastructure equipment. Koomey distinguishes in [31] an upper bound value of 1.92 (based on [35]) and a lower bound value of 1.83 (based on [36]). We assume an average PUE of 1.88 for the year 2010. Based on a PUE of 2 for the year 2005, we linearly interpolated the intermediate years, and linearly extrapolated this trend for the years beyond 2010. This results in a PUE of 1.95 for 2007 and a PUE of 1.83 for 2012, as shown in Table 3.

\subsection{Result}

Our results show that data centers worldwide consume 270 TWh in 2012, as shown in Fig. 4. The CAGR from 2007 to 2012 is $4.4 \%$. The data center power consumption is dominated by infrastructure electricity use (i.e., cooling and power supply losses). The actual server power consumption accounts for only about $40 \%$ (see Fig. 4), and is clearly dominated by the share of volume servers (see Table 3 ).

\subsection{Reliability}

Our estimation is mainly based on [31], as it provides the most substantiated values available on this subject. There are few studies that provide an estimate for the worldwide data center electricity use, and most of them either base themselves on the same study (or an earlier publication from the same author), or are outdated for the time frame we consider.

An important uncertainty in [31] is related to the power per server in 2010. Our analysis of spec.org data leads us to believe that a stagnation in power per server since 2005 is more likely than a continuation of the pre-2005 power-per-server trends.

The PUE value is a second factor that is rather uncertain. As any changes to the PUE apply linearly to the result, the impact of any deviation is potentially large. A worldwide data center survey conducted in 2012 by the UptimeInstitute [37] reports that the PUE reported by its participants averages between 1.8 and 1.89. While this value might be biased (as data centers 


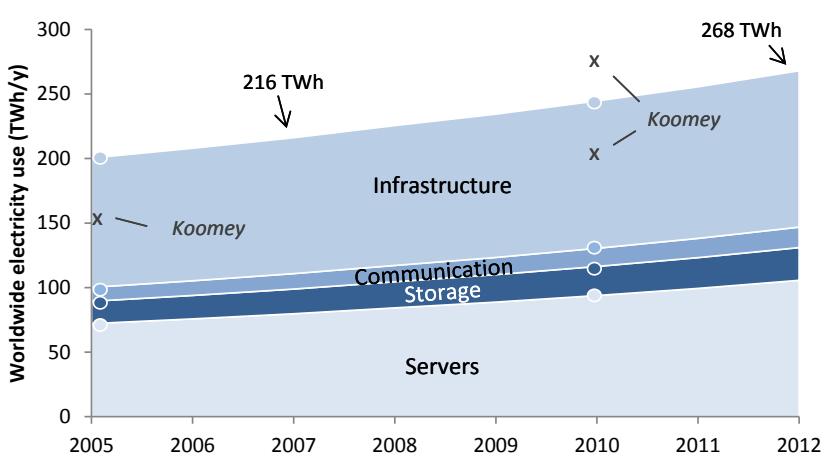

Figure 4: Worldwide use phase electricity consumption of data centers. Infrastructure electricity use (mainly cooling and power supply losses) dominate the result, followed by the electricity used by the actual servers. The three crosses indicate Koomey's values for 2005 and 2010 (upper bound an lower bound) [31] While our results in general follow Koomey's lower bound assumptions, they are shifted upwards (and, incidentally, close to the average of the 2010 lower and upper bound value) since we account for orphaned servers. The circular markers $\circ$ indicate years for which the subcategory results are (mainly) based on data for that specific year; non-marked data points are (mainly) interpolations or extrapolations.

with a focus on energy-efficiency are more likely to report their results) it is in line with the value we extrapolated for 2012, i.e. 1.83 , which increases the confidence in our results.

Finally, our accounting for orphaned servers based on a value that was reported, but not used, by Koomey, might raise some criticism, and rightly so. However, we think the actual worldwide power consumption is better approximated by including it. As it is applied as a single factor across all years considered, it does not influence the observed growth trend.

\section{Overall trends and observations}

In the previous sections we discussed the electricity use of three categories-communication networks, personal computers, and data centers - separately. Here, we compare their trends and absolute power consumption values to each other, to remaining ICT equipment categories (such as TVs and mobile phones) and to the total worldwide electricity use.

All values in this section apply to the time frame 2007 to 2012.

\subsection{Growth trends}

Communication networks show the highest increase of electricity use, with a CAGR of $10.4 \%$ (see Fig. 5). The growth rates of PCs and data centers are both only about half of that value. All three growth rates are higher than the growth rate of the total worldwide electricity consumption (about $3 \%$ per year $^{5}$ ) [38]. This implies that the share of these ICT categories

${ }^{5}$ The CAGR of the worldwide electricity consumption from 2000 to 2011 is $3.4 \%$. We used this long-term trend to extrapolate the 2011 value to 2012 . The CAGR from 2007 to 2012 is slightly lower at $2.9 \%$ because of the impact of the global financial crisis in 2008 and in the subsequent years.

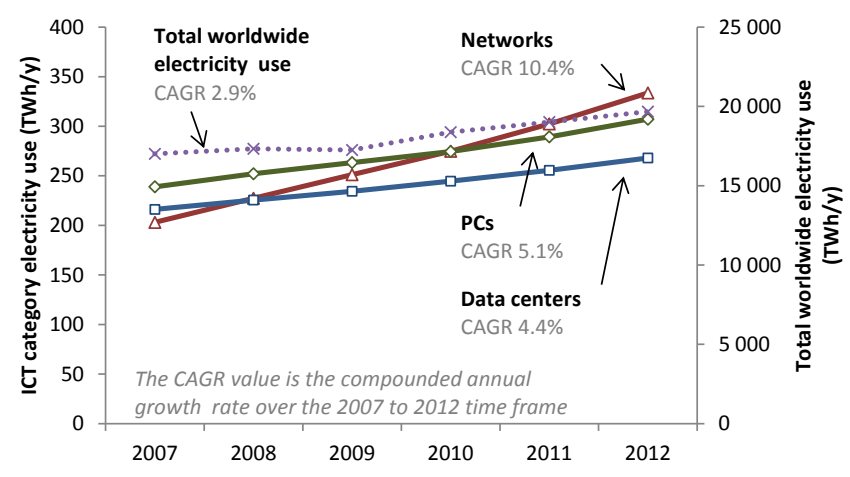

Figure 5: Evolution of worldwide electricity use of networks, PCs and data centers (solid lines, left axis) and total worldwide electricity use (dotted line, right axis). Over the last five years, the electricity consumption in all three ICT categories increased at a rate higher than the total worldwide electricity consumption. In 2012 each category accounts for roughly $1.5 \%$ of the worldwide electricity consumption. Note that, since some of the data points between 2007 and 2012 are based on interpolations, small variations might not show up in the intermediate years.

in the total worldwide electricity consumption is increasing year after year.

The observed growth rates are lower than what we projected in our earlier study by Pickavet et al. [5] in 2008; we then estimated the growth in a business as usual scenario to be $12 \%$ per year for communication networks, nearly $8 \%$ per year for personal computers, and $12 \%$ per year for data centers. While part of this difference might be attributed to the uncertainty associated with our estimates, we see two other potential reasons for this significant decrease in growth rates. First, the increased attention for more energy-efficient technologies has brought down the electricity use growth rates. This is clearly visible in the personal computer category, with the shift from CRT to LCD monitors, and from desktop to laptop computers. Second, it is not unlikely that the global financial crisis from 2008 had an impact on the buying behavior of end-users and businesses related to ICT equipment, and consequently the associated electricity use. It is important to point out that - as the main intention of our study was to capture the growth trend from 2007 to 2012 some data points are the result of interpolation and extrapolation. Therefore, variations in intermediate years might not show up in our results.

Communication networks - We cannot easily attribute the relatively high growth in communication networks to a specific factor. Telecom operator networks dominate the communication network power consumption (see Fig. 2), and they are the main driver for the growth. However, as explained earlier in Section 2.1, our methodology does not allow for a further breakdown of power consumption across mobile, fixed broadband and fixed telephony services. The worldwide number of mobile subscriptions and fixed broadband subscriptions show an increase of $13 \%$ to $14 \%$ per year [7], the number of fixed telephony subscribers has decreased at a rate of $1 \%$ per year. With the growth rate of mobile and fixed broadband subscriptions being somewhat higher than the growth rate of the electricity use in telecom operator networks, it is likely that the electricity 
consumption per average subscriber is decreasing. It is however not clear if this can be attributed to the (intentional) replacement of old equipment with more energy-efficient devices, or if this is rather because of a shift to new technologies such as mobile communication.

Personal computers - The relatively modest growth in PC power consumption is attributed to a shift to more powerefficient technologies, notably from desktops to laptops and from CRT monitors to LCDs. For this reason, while the number of computers and monitors have grown at a rate of $11-12 \%$, total PC electricity use has grown at a rate of just over $5 \%$ per year.

Data centers - The increase in the number of servers drives the growth in data center electricity use, despite the slight improvement in PUE. As volume servers dominate the data center power consumption (see Table 3 ), their growth rate (at $5.9 \%$ p.a.) drives the overall data center electricity growth rate. The growth rate for data centers ( $5.1 \%$ per year) is significantly lower than what we estimated five years ago (12\% per year). This is due to a reduced growth in number of servers (caused by the 2008 financial crisis, the associated economic slowdown, and further improvements in virtualization [31]) and the assumed stagnation in power per server. Especially in medium to large data centers, the incentive for actions to improve the energy-efficiency can lead to very visible reductions in electricity use (and associated costs), while these actions are at the same time relatively easy to implement due to economies of scale. In locations with only a few servers, on the other hand, the server electricity use is probably a relatively minor cost, and consequently less of a focus for improvements or optimizations.

Cross-domain observations - In [39] it is observed that 'the electrical efficiency of computation has doubled roughly every year and a half over the last six decades'; this corresponds to an annual reduction of $38 \%$ in power per unit of computation. It is interesting to note that this trend-which applies to laptops, desktops and servers in our study - has not resulted in a reduction or even status quo of the overall power consumption of these devices. Instead, it appears that precisely this powerefficiency trend leads to the emergence of new technologies such as laptops and mobile phones. These, in turn, have led to new services and applications leading to an overall increase in ICT power consumption. In this light, it is interesting to observe that our results do not indicate (yet) that laptops have replaced desktops (in Fig. 3 there is no decline in desktop power consumption); laptops appear to be used in addition to the already existing worldwide user base of desktops.

Similarly, anecdotal evidence suggests that network operators have a tendency to build new networks on top of existing networks, leaving older equipment in place for supporting legacy devices and services. This suggests that the equipment lifetime for network equipment is much longer than for PCs and servers, which might partly explain the higher growth rate for power consumption in communication networks when compared to the other two categories.

\subsection{Relative power consumption}

The three categories were each consuming roughly an equal amount of power in 2007. The relatively high growth rate of communication networks electricity use has lead to this category to overtake the power consumption of both PCs and data centers in 2012 (see Fig. 5).

Still, each of these categories only accounts for a small share of the total worldwide electricity consumption, respectively $1.7 \%$ for networks, $1.6 \%$ for PCs and $1.4 \%$ for data centers in 2012 .

\subsection{Power consumption of the remaining ICT equipment}

For reference, and to provide a 'bigger picture' view, we have also tried to estimate the power consumption of the remaining ICT equipment. We explicitly point out that the estimates below are provided to give a rough indication only. We have grouped these in two categories, i.e. TVs and Others.

$T V s$ - We estimate the worldwide TV power consumption in 2012 to be in the order of $400-500$ TWh. This estimation is mainly based on combining the results in [19] (which provides a detailed estimation of TV electricity use in the USA) and [40] (which estimates the worldwide TV electricity consumption based on present and future TV energy-efficiency levels, but doesn't seem to take into account the electricity consumption of legacy TVs).

Other ICT equipment - We estimate the worldwide power consumption of other ICT equipment to be in the order of 300 - 500 TWh. While the 'others' category by definition comprises all remaining ICT equipment, we have based ourselves on the OECD definition of $\mathrm{ICT}^{6}$, but included in our estimation only those categories which we believe to represent the bulk of the electricity consumption. More specifically we have included the following equipment in our estimate (roughly from largest to smallest share): set-top boxes, general other household ICT equipment (such as radios, hi-fi systems, cordless phones, docking stations and VCRs), DVD and blu-ray players/recorders, video game consoles, general office ICT equipment (such as printers, faxes, scanners, telephony equipment and audio/visual equipment), mobile phones, computer speakers, household printers, and ATMs. Note that we did not take into account point-of-sale terminals, PDAs, burglar or fire alarms, TV cameras, tablets and electronic integrated circuits integrated in devices generally not considered as ICT (for example, the control electronics inside washing machines). Tablets are not specifically identified yet in the OECD definition (although they fit under 'portable automatic data processing machines weighing not more than $10 \mathrm{~kg}$, such as laptop and notebook computers'); however, we show in Section 6.2 that their electricity use is still negligible.

Our rough estimates for TVs and Other ICT equipment suggest that our three categories-communication networks, personal computers and data centers-account for about half of the

\footnotetext{
${ }^{6}$ As ICT starts to entangle all aspects of our lives, the scope of what exactly ICT equipment (and services) comprises is becoming increasingly difficult to define. The OECD probably provides the best documented scope of 'ICT products' in Table 2.A1.1 of [41]. Another approach, proposed and used in [42], would be to abandon the usage of the term ICT altogether, and consider instead 'Electronics' which is defined as 'any device whose primary function is information'.
} 
worldwide ICT electricity use. This would mean that the use phase of ICT accounts for around $9 \%$ of the total worldwide electricity consumption in 2012. However, as we mentioned earlier, the above statements have to be treated with caution, since our estimates for TVs and Other ICT equipment are only rough estimations to perform a first-order comparison.

\section{Comparison with other studies}

In this section we compare our results to those of a number of other studies in order to get an indication of the validity of our results. We look at an earlier estimate of our research group [5] published in 2008, the SMARTer2020 report published in 2012 [6] which is a follow-up to the well-known SMART2020 report from 2008 [3], and work published in 2010 by Malmodin et al. [2].

Fig. 6 shows our results for the year 2012 and the results of the four said works for their respective applicable year. The bars represent the electricity use (in TWh) for each of the three categories, broken down into subcategories if detailed values were available or could be derived. The observed or projected annual growth rate is indicated between brackets. Triangles indicate our estimate for the corresponding year. For clarity, the observed and projected annual growth rates are also reported in Table 4.

The works by Raghavan [43] and Somavat [44] are two recent studies that provide estimates for the ICT categories we consider. Although we mention them here for completeness, the estimates in [43] are too crude for our purpose. The estimates in [44] are roughly in line with our findings, which is not surprising as they are partly based on our earlier work [5] and Koomey's work [45].

Table 4: Comparison of historical and projected annual growth rates in worldwide electricity use. Our estimates for 2007 to 2012 are lower than all projections for 2020, two exceptions notwithstanding.

\begin{tabular}{lcccc}
\hline & $\begin{array}{c}\text { This study } \\
\text { (estimated } \\
\text { 2007-2012) }\end{array}$ & $\begin{array}{c}\text { SMART2020 } \\
\text { (projected } \\
\text { 2002-2020) }\end{array}$ & $\begin{array}{c}\text { Pickavet2008 } \\
\text { (projected } \\
\text { 2007-2020) }\end{array}$ & $\begin{array}{c}\text { SMARTer2020 } \\
\text { (projected } \\
2011-2020)\end{array}$ \\
\hline Networks & $10.4 \%$ & $4.6 \%^{\mathrm{a}}$ & $12.0 \%$ & $11.5 \%$ a \\
PCs & $5.1 \%$ & $5.2 \%$ & $7.5 \%$ & $-1.8 \%$ \\
Data centers & $4.4 \%$ & $7.0 \%$ & $12.0 \%$ & $7.1 \%$ \\
\hline
\end{tabular}

${ }^{a}$ Telecom operator network subcategory only

\subsection{Communication networks}

Note: a more detailed comparison of communication networks electricity use is available in [7]. It contains a wider set of related works, but does not include the SMARTer2020 report [6] which was not yet available at the time.

It is clear from Fig. 6 that our estimate of network electricity use is (significantly) higher than earlier/other estimates. We think the main reason for this is because our methodology captures the (hidden) overhead associated to operators in a more accurate way.

The 2007 value from Malmodin et al. [2] for the CPAE subcategory is in line with our results for 2007, being $31 \mathrm{TWh}$.

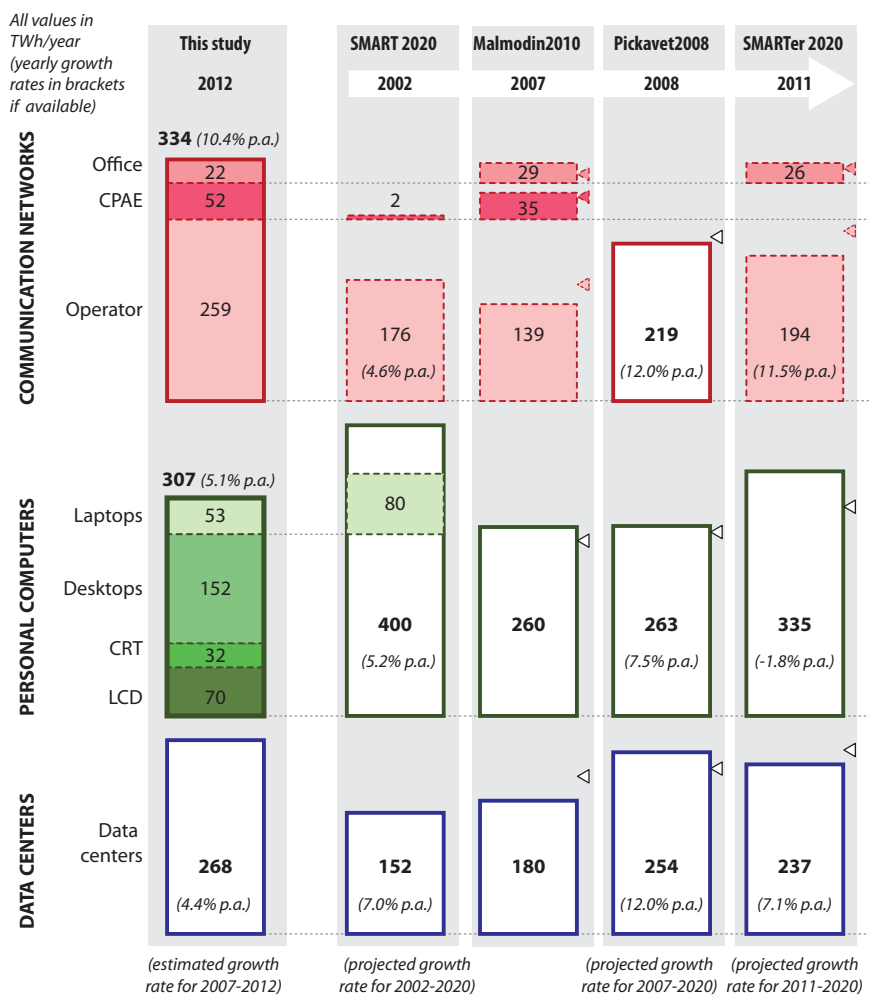

Figure 6: A comparison of our 2012 results with a number of other often-cited studies $[3,2,5,6]$. These works have been ordered by year of applicability. The triangles to the right of the boxes indicate, for easier comparison, our estimation for the applicable year. The SMART2020 report values have been derived from the use phase $\mathrm{CO}_{2}$ values assuming $500 \mathrm{gCO}_{2} / \mathrm{kWh}$.

Their value for office networks is more than twice as high as our estimation (i.e., 12 TWh). Malmodin assumes a fixed overhead of 8 watts for each office PC, which-as we mentioned in Section 2.5-potentially includes office end-user equipment (such as faxes) that is out of our scope. The 2007 value from Malmodin for operator networks (139 TWh) includes overhead for offices and stores. To bring this in agreement with our scope, we should subtract this overhead, which we estimated in [7] to be about $13 \%$. If we do so, their result for operator networks (121 TWh) is about $25 \%$ lower than our value (i.e., $160 \mathrm{TWh}$ for 2007). This difference can probably be attributed to the fact that they used a different sample and did not distinguish between fixed broadband and fixed telephony users in their calculation method.

The 2008 value from our earlier work (Pickavet et al. [5]) is only about $2 \%$ lower than our current value for 2008 . On the other hand, because of the adjusted growth rates, our earlier estimate for 2012 is $3 \%$ higher than our current value for 2012.

As the SMARTer2020 report [6] based its network electricity consumption estimation on the study by Malmodin, we see similar deviations from our results, i.e. a lower estimation for the operator subcategory, and a higher estimation for the office sub- 
category ${ }^{7}$. However, the deviation in the office subcategory from our results is only $30 \%$, which is lower than what we observed for Malmodin's study. This is because the SMARTer2020 report assumed 4 watts for network equipment per office PC, or half of Malmodin's value ${ }^{8}$. While $4 \mathrm{~W} / \mathrm{unit}$ is slightly lower than our 4.4 W/unit for 2011, the higher number of office PCs in the SMARTer2020 report results in an overall higher value for office network electricity consumption.

\subsection{Personal computers}

We have a consistently lower estimate for the worldwide electricity use by personal computers and monitors compared to the other works. The main reason seems to be that we estimate the average yearly electricity use per PC setup lower than other works. An overview is given in Table 5. This is somewhat surprising, as we are using USA-based data, which we thought might lead to an overestimation. A study dedicated to mapping variations in the average yearly PC electricity consumption across different worldwide regions would certainly be beneficial to clear up this issue.

Table 5: Comparison of the average energy consumption ( $\mathrm{kWh} /$ year) per PC (inc. monitor). For this study, the values are obtained by dividing the total power consumption of laptops, desktops and monitors by the total number of laptops and desktops.

\begin{tabular}{lccccc}
\hline Applicable year & 2007 & 2008 & 2011 & 2012 & 2020 \\
\hline This study & 221 & 208 & 177 & 169 & - \\
Malmodin2010 [2] & 250 & - & - & - & - \\
Pickavet2008 [5] & - & 263 & - & - & - \\
SMARTer2020 [6] & - & - & 219 & - & 102 \\
\hline
\end{tabular}

Malmodin's [2] value for the worldwide electricity use of PCs in 2007 is about $9 \%$ higher than our value. While the worldwide total number of computers for 2007 is very similar, Malmodin's average power consumption per PC (including monitors) is approximately $13 \%$ higher than our average value for the same year.

The estimate in our earlier work [5] for 2008 is $4 \%$ higher than our current value for 2008. The shift to more powerefficient technologies such as laptops and LCD monitors explains the reduced annual growth rate in electricity use; our earlier work was based on the number of computers growing at about $10 \%$ per year, which is similar to our current observed value of $11-12 \%$ (see Section 3.5).

The 2011 estimate by the SMARTer2020 report [6] is $16 \%$ higher than our estimate. While their assumed installed base of PCs is slightly lower than our numbers, again the higher electricity use per personal computer results in a higher total worldwide electricity use for personal computers. Interestingly, they

\footnotetext{
${ }^{7}$ We do not have a SMARTer2020 report value for the CPAE subcategory. The SMARTer2020 report states that 'set top boxes, home routers and modems and other computer peripherals' account for $13 \%$ of the overall end-user device emissions. This cannot be mapped directly to electricity use of our CPAE subcategory.

${ }^{8}$ This is probably because the SMARTer2020 report left out office end-user equipment such as faxes, which make up about half of Malmodin's $8 \mathrm{~W} /$ unit.
}

forecast a $-1.8 \%$ compounded annual decrease for PC electricity use from 2011 to $2020^{9}$. The reason behind this downward trend is the halving of the average electricity use per device by 2020 , driven by both 'efficiency gains and fewer hours spent on PCs due to the emergence of smart devices, and a greater use of laptops vs. desktops' [6]. We can not yet observe this trend in our estimates, see Fig. 3.

With the recent explosion of tablet device sales-the first Apple iPad was released mid 2010, and over 100 million devices had been sold by the end of 2012 [46] — it might be interesting to point out that the SMARTer2020 report estimates the tablet worldwide electricity use in 2011 at 1.1 TWh (but sharply increasing at $36 \%$ annually towards the year 2020). Even at a projected 1.5 TWh in 2012, this is-for now-still a negligible $0.5 \%$ fraction of the total electricity use of the PCs category.

\subsection{Data centers}

It is important to point out that all works depicted in Fig. 6 (including this study) based their data center electricity use estimation on work by Koomey et al. [47][45][31]. There is good reason for this, as his work is backed up by solid data (that might otherwise be very hard to have access to) and a transparent methodology. With this in mind, we would expect consistent results across all works. However, we can see in Fig. 6 that this is not always the case. The reason is twofold.

First, in this study we have accounted for the electricity use of 'orphaned servers', i.e., a typically undocumented number of servers using electricity but no longer delivering services. While Koomey himself provides an estimate of this share, he considers the value too unreliable to include in his calculations. Nonetheless, we think the actual worldwide electricity use of data centers is better reflected when we include this share, which represents an additional $25 \%$ in electricity use over the non-inclusion scenario. This explains the lower estimates for 2008 by Malmodin [2] and for 2011 by the SMARTer2020 report [6]. The difference with the SMARTer2020 report value (237 TWh) is less than the expected 25\%; the reason is that the report uses the average of Koomey's upper and lower bound scenarios, while our results are based on the lower bound power-per-server values.

Second, our earlier work (Pickavet et al. [5]) was based on initial work by Koomey in [47] which provided an estimate for the year 2005. Later on however, Koomey refined his estimate for 2005 in [45] and [31], especially with respect to the estimation of the storage and communications overhead. The result was that we overestimated this overhead for 2008. In addition, Koomey showed in [31] that the growth in electricity use after 2005 was not as high as projected earlier, which again lead to an overestimation for 2008 from our side. However, the overestimation in our earlier work compared to this current study is not as high as could be expected from both these hindsight

\footnotetext{
${ }^{9}$ In contrast, the total $\mathrm{CO}_{2}$ emissions by PCs, consisting of both the electricity usage carbon emissions and the embodied emissions, is forecast by the SMARTer2020 report to increase with $1.2 \%$ per year from 2011 to 2020 . This is due to the embodied emissions in the increasing number of shipments. It is not clear whether shipments are estimated to increase due to a growing user base, shorter device lifetimes, or both.
} 
observations, because it is dampened by the effect of accounting for orphaned servers, as described above.

\section{Conclusion and outlook}

\subsection{Conclusion}

Growth trends - The combined electricity consumption of communication networks, personal computers and data centers is growing at a rate of nearly $7 \%$ per year (i.e., doubling every 10 years). The strongest growth is observed in communication networks, at $10 \%$ per year, probably fueled by the increase in (mobile) interconnectivity of digital equipment. The electricity consumption of personal computers is growing at $5 \%$ per year, and that of data centers at $4 \%$ per year. All growth rates have decreased compared to what we predicted in a similar study five years ago. This can partly be attributed to a shift to more energyefficient technologies (such as from CRT to LCD monitors, and the introduction of server virtualization), and potentially to the effects of the global financial crisis in 2008.

Absolute power consumption - Together these three ICT categories consumed about 900 TWh in 2012. The relative share of these ICT products and services in the total worldwide electricity consumption has increased from about $3.9 \%$ in 2007 to $4.6 \%$ in 2012. This does not yet include the electricity consumption of other devices that are usually considered as part of ICT, such as TVs and their set-top boxes, (smart) phones and audio devices.

Focus of reduction efforts - The electricity consumption of each of the three considered categories is about the same size. This highlights the need for energy-efficiency research across all three domains, rather than focusing on a single one. On the other hand, it might be useful for future work to rethink the breakdown of ICT electricity use in the presently considered categories. Perhaps an assessment on e.g. displays or general overhead (such as power-supply and standby losses), might lead to new insights on where the main focus should be.

Comparison to other studies — Our results are also consistent with other research on this topic. A notable exception is that we consistently estimate the electricity use attributed to telecom operator networks higher than other works. We attribute this to our methodology which we think is more inclusive and representative of the actual electricity use in this subcategory.

\subsection{Reflections and outlook beyond 2012}

While the last decade has seen an increasing attention for energy-efficiency, this has not yet translated in an absolute reduction or even status quo of the total ICT electricity use. Indeed, the growth of some specific (sub)categories has slowed down, but there is a shift to new applications and technologies such as LCDs, laptops, and tablets. While these devices have smaller electricity usage, this energy-efficiency improvement is outweighed (or soon could be) by a fast growth in device numbers. In this light, it might be interesting to research to which extent an increase in energy-efficiency has made the continued growth in ICT services possible, and thus partly fueled the associated growth in ICT electricity use as well.
Finally, looking beyond 2012, it is difficult to predict future growth rates. Personal computers will probably become even more efficient as the world continues to move to more mobile forms of end-user computing devices, potentially resulting in a stabilization or even decline in total electricity use. The electricity consumption in communication networks might continue to increase at the current rate, with more and more devices being connected and the advent of machine-to-machine communication (for example, your electric utility company could be telling your washing machine to start when a surplus of renewable energy becomes available). In addition, while the percentage of individuals using the Internet in emerging economies such as China and India is steadily rising, it is still far below those in more mature markets such as the USA, Western Europe and Japan. Concerning data center power consumption, we see two opposite trends. The increasing popularity of cloud-based computing and storage could result in more servers (and an associated increase in electricity consumption). On the other hand, this might also be an opportunity to move servers running at low overall efficiency in small offices and companies to more energy-optimized data centers.

In the future, frequent estimates of the worldwide electricity use by ICT will be essential to provide timely feedback if indeed ICT electricity consumption remains relatively small, or instead continues to grow at an unsustainable rate.

\section{Acknowledgments}

The work described in this paper was carried out with the support of the iMinds-project GreenICT, the European Community's Seventh Framework Programme (FP7/2007-2013) under grant agreement n. 247674 (STRONGEST project), n. 257740 (Network of Excellence TREND), and n. 288021 (Network of Excellence EINS). Sofie Lambert is funded by the Agency for Innovation by Science and Technology in Flanders (IWT).

\section{References}

[1] G. A. Fowler, Facebook: One billion and counting, The Wall Street Journal, 2012. Available at: http://online.wsj.com/article/ SB10000872396390443635404578036164027386112.html.

[2] J. Malmodin, A. Moberg, D. Lundn, G. Finnveden, N. Lvehagen, Greenhouse gas emissions and operational electricity use in the ICT and entertainment \& media sectors, J. Ind. Ecol. 14 (2010) 770-790. doi: $10.1111 /$ j. $1530-9290.2010 .00278 . x$.

[3] M. Webb et al., SMART2020: Enabling the low carbon economy in the information age, The Climate Group, 2008. Available at http://www smart2020.org/_assets/files/02_Smart2020Report.pdf.

[4] P. Teehan, M. Kandlikar, Sources of variation in life cycle assessments of desktop computers, Journal of Industrial Ecology 16 (2012) S182-S194.

[5] M. Pickavet, W. Vereecken, S. Demeyer, P. Audenaert, B. Vermeulen, C. Develder, D. Colle, B. Dhoedt, P. Demeester, Worldwide energy needs for ICT: the rise of power-aware networking, in: 2nd International Symposium on Advanced Networks and Telecommunication Systems, 2008 (ANTS '08), pp. 1-3. doi:10.1109/ANTS.2008.4937762.

[6] GeSI and BCG, SMARTer2020: The Role of ICT in Driving a Sustainable Future, 2012. Available at: http: //gesi .org/SMARTer2020.

[7] S. Lambert, W. Van Heddeghem, W. Vereecken, B. Lannoo, D. Colle, M. Pickavet, Worldwide electricity consumption of communication networks, Optics Express 20 (2012) B513-B524. doi:10.1364/OE.20.00B513. 
[8] D. Kilper, G. Atkinson, S. Korotky, S. Goyal, P. Vetter, D. Suvakovic, O. Blume, Power trends in communication networks, IEEE Journal of Selected Topics in Quantum Electronics 17 (2011) 275 -284. doi:10.1109/JSTQE.2010.2074187.

[9] J. Baliga, R. Ayre, K. Hinton, W. V. Sorin, R. S. Tucker, Energy consumption in optical IP networks, J. Lightwave Technol. 27 (2009) 2391-2403. doi:10.1109/JLT.2008.2010142.

[10] S. Lanzisera, B. Nordman, R. Brown, Data network equipment energy use and savings potential in buildings, Energy Efficiency 5 (2012) 149-162. doi:10.1007/s12053-011-9136-4.

[11] HomePlug PowerLine Alliance, HomePlug Certifies Products Based On Newly Ratified IEEE 1901 Powerline Networking Standard, 2010. Press release available at: https://www.homeplug.org/news/pr/view? item_key=871577ee4d3afd08e7d9ccf1a6300061add3681a.

[12] devolo, dLAN 200 AVplus Starter Kit, 2012. Data sheet available at: http://www.devolo.com/consumer/dlan-200-avplus/pdf/ datasheet-dlan-200-avplus-starter-kit-en.pdf.

[13] Solwise, NET-PL-200AV-MINI, 2013. Available at: http://www solwise.co.uk/net-powerline-av-mini.htm.

[14] ITU, Global ICT developments, 2001-2011, ITU World Telecommunication / ICT Indicators database, 2011. Available at: http: //www . itu . int/ITU-D/ict/statistics.

[15] UN, World population prospects: the 2010 revision, UN Population Division, 2011. Available at: http://data.un.org/Data.aspx?q= population\&d=PopDiv\&f=variableID\%3a12.

[16] Point-Topic, World broadband statistics: Q4 2007, Point-Topic, 2008.

[17] Point-Topic, World broadband statistics: Q4 2011, Point-Topic, 2012.

[18] The World Bank, The little data book on information and communication technology, The World Bank / ITU, 2007-2012.

[19] B. Urban, V. Tiefenbeck, K. Roth, Energy consumption of consumer electronics in U.S. homes in 2010., Fraunhofer Center for Sustainable Energy Systems, 2011.

[20] C. Cremer, W. Eichhammer, M. Friedewald, P. Georgieff, S. Rieth-Hoerst, B. Schlomann, P. Zoche, B. Aebischer, A. Huser, Energy consumption of information and communication technology (ICT) in Germany up to 2010 summary of the final report to the German federal ministry of economics and labour, 2003.

[21] W. Vereecken, W. Van Heddeghem, M. Deruyck, B. Puype, B. Lannoo, W. Joseph, D. Colle, L. Martens, P. Demeester, Power consumption in telecommunication networks: overview and reduction strategies, IEEE Commun. Mag. 49 (2011) 62-69. doi:10.1109/MCOM.2011.5783986.

[22] C. Lange, D. Kosiankowski, R. Weidmann, A. Gladisch, Energy consumption of telecommunication networks and related improvement options, IEEE Journal of Selected Topics in Quantum Electronics 17 (2011) 285-295. doi:10.1109/JSTQE.2010.2053522.

[23] K. Kawamoto, J. Koomey, B. Nordman, R. Brown, M. Piette, M. Ting, A. Meier, Electricity used by office equipment and network equipment in the US, Energy 27 (2002) 255-269. doi:10.1016/S0360-5442(01)00084-6.

[24] ITU, Definitions of world telecommunication/ICT indicators, ITU, 2010. Available at: http://www.itu.int/ITU-D/ict/material/ TelecomICT_Indicators_Definition_March2010_for_web.pdf.

[25] UN, Millennium development goals indicators, UN Statistics Division, 2010. Available at: http://mdgs . un.org/unsd/mdg/Data. aspx.

[26] Asymco, A brief history of personal computer vendors, Available at: http://www.asymco.com/hire-me/ historic-computer-shipments/, 2011.

[27] M. Murphy, M. Meeker, KPCB top mobile internet trends, Available at: http://www.slideshare.net/kleinerperkins/ kpcb-top-10-mobile-trends-feb-2011, 2011.

[28] F.-K. Wang, K.-K. Chang, Modified diffusion model with multiple products using a hybrid GA approach, Expert Systems with Applications 36 (2009) 12613 - 12620. doi:10.1016/j.eswa.2009.05.018.

[29] Australian Computer Society, Carbon and computers in Australia - the energy consumption and carbon footprint of ICT usage in Australia in 2010, ACS, 2010

[30] A. Andrae, O. Andersen, Life cycle assessments of consumer electronics - are they consistent?, The International Journal of Life Cycle Assessment 15 (2010) 827-836. doi:10.1007/s11367-010-0206-1.

[31] J. G. Koomey, Growth in data center electricity use 2005 to 2010, Available at: http://www.analyticspress.com/datacenters.html, 2011.
[32] spec.org, SPECpower ssj2008 benchmark, http://www.spec.org/ benchmarks.html, 2013. Data used up to (and including) December 2012.

[33] IDC, Despite a 7.2\% Decline in Fourth Quarter Revenue, Worldwide Server Market Revenues Increase $5.8 \%$ in 2011, According to IDC, 2012. Press release available at: http://www.idc.com/getdoc.jsp? container Id=prUS23347812.

[34] IDC, Worldwide Server Market Rebounds Sharply in Fourth Quarter as Demand for $\mathrm{x} 86$ Servers and High-end Systems Leads the Way, According to IDC, 2013. Press release available at: http: //www . idc . com/getdoc . jsp? containerId=prUS23974913.

[35] Energy Star, Performance Ratings Technical Methodology for Data Center, Energy Star, 2010. Available at: http://www.energystar. gov/ia/business/evaluate_performance/data_center_tech_ desc.pdf.

[36] Uptime Institute, 2011 Data Center Industry Survey, Uptime Institute, 2011

[37] M. Stansberry, J. Kudritzki, Uptime Institute 2012 Data Center Industry Survey, Uptime Institute, 2012. Available at: http:// uptimeinstitute.com/2012-survey-results.

[38] Enerdata, Global energy statistical yearbook 2012, Enerdata, 2012. Available at: http://yearbook.enerdata.net/ world-electricity-production-map-graph-and-data.html.

[39] J. G. Koomey, S. Berard, M. Sanchez, H. Wong, Implications of historical trends in the electrical efficiency of computing, Annals of the History of Computing, IEEE 33 (2011) 46-54. doi:10.1109/MAHC.2010.28.

[40] W. Park, A. Phadke, N. Shah, V. Letschert, TV Energy Consumption Trends and Energy-Efficiency Improvement Options, Technical Report LBNL-5024E, Ernest Orlando Lawrence Berkeley National Laboratory, 2011. Available at: http://www.superefficient.org/en/ Resources/ /media/Files/SEAD\%20Televisions $\% 20$ Technical\% 20Analysis.pdf.

[41] OECD, OECD Guide to Measuring the Information Society 2011, OECD Publishing, 2011. doi:10.1787/9789264113541-en.

[42] B. Nordman, S. Lanzisera, Electronics and network energy use: Status and prospects, in: IEEE International Conference on Consumer Electronics (ICCE) 2011, pp. 245-246. doi:10.1109/ICCE.2011.5722564

[43] B. Raghavan, J. Ma, The energy and emergy of the internet, in: Proceedings of the 10th ACM Workshop on Hot Topics in Networks, ACM, p. 9. doi:10.1145/2070562.2070571.

[44] P. Somavat, V. Namboodiri, Energy consumption of personal computing including portable communication devices, Journal of Green Engineering 1 (2011) 447-475

[45] J. G. Koomey, Worldwide electricity used in data centers, Environmental Research Letters 3 (2008). doi:10.1088/1748-9326/3/3/034008.

[46] B. X. Chen, Apple, facing competition, introduces a smaller ipad of no significant change, The New York Times, 2012. Available at: http://www.nytimes.com/2012/10/24/technology/ apple-facing-competition-introduces-a-smaller-ipad. html.

[47] J. G. Koomey, Estimating total power consumption by servers in the US and the world, 2007. Available at: http://hightech.lbl.gov/ documents/DATA_CENTERS/svrpwrusecompletefinal.pdf. 